\title{
Achieving Value in Primary Care: The Primary Care Value Model
}

William Rollow, MD, MPH

Peter Cucchiara, BSMIS, MBA ${ }^{2}$

'Family and Community Medicine, University of Maryland School of Medicine, Baltimore, Maryland

${ }^{2} \mathrm{New}$ Jersey Innovation Institute, New Jersey Institute of Technology, University Heights Newark, New Jersey

Conflicts of interest: authors report none.

\section{CORRESPONDING AUTHOR}

William Rollow, MD, MPH 11884 Bright Passage

Columbia, MD 21044

wrollow@aol.com

\begin{abstract}
The patient-centered medical home (PCMH) model provides a compelling vision for primary care transformation, but studies of its impact have used insufficiently patient-centered metrics with inconsistent results. We propose a framework for defining patient-centered value and a new model for value-based primary care transformation: the primary care value model (PCVM). We advocate for use of patient-centered value when measuring the impact of primary care transformation, recognition, and performance-based payment; for financial support and research and development to better define primary care value-creating activities and their implementation; and for use of the model to support primary care organizations in transformation.
\end{abstract}

Ann Fam Med 2016;14:159-165. doi: 10.1370/afm.1893.

\section{INTRODUCTION}

$\mathrm{T}$ ransformational change is required to achieve substantial improvement in health care outcomes and costs. In primary care, the patient-centered medical home (PCMH) model has gained acceptance as the guiding vision for transformation since explication of its principles in a joint statement by primary care specialty societies in 2007. ${ }^{1}$ Evaluation of the model, however, has produced inconsistent results with varying interpretations. ${ }^{2-12} \mathrm{~A}$ more patient-centered view of value should guide subsequent evaluation, and the model should correspondingly evolve to better support achievement of such value.

\section{STUDIES OF PCMH MODEL IMPACT}

A 2012 review of studies assessing the impact of practice transformation that included 3 or more elements of PCMH found evidence to be of low quality, with some favorable but largely inconclusive effects on processes and outcomes of care, use of emergency departments and hospital admissions, and patient experience. ${ }^{2}$ A 2014 review of initiatives meeting requirements for $\mathrm{PCMH}$ and using randomized or controlled methods found a small to moderate positive impact on patient experience, preventive care, and emergency department use, but no impact on overall cost. ${ }^{3}$ A 2015 review including all articles identified in a search for PCMH found reductions in health care use and cost, and improvement in quality and patient experience metrics in some peer-reviewed and non-peer-reviewed reports. ${ }^{4}$ Other studies published within the past 3 years have shown similarly varying results. ${ }^{5-9}$

\section{Interpreting Mixed Findings}

These mixed findings have been interpreted in differing ways by reviewers, ${ }^{10-12}$ for a number of possible reasons.

\section{Methodological Challenges}

Often, studies have tracked performance for periods of only a year or 2 among small numbers of clinicians. 
PCMH Recognition May Not be a Valid Indicator of Model Adoption

The National Committee for Quality Assurance (NCQA) - whose recognition program is the most widely used in studies-has explicitly sought to raise the bar in recognition requirements over time, ${ }^{13}$ and other programs have similar requirements. ${ }^{14,15}$ But recognition does not require defined levels of performance on outcome measures, and practices achieving recognition differ substantially in the extent to which they have adopted the model, particularly given differences in the amount of PCMH funding they have received.

The Existing PCMH Model May Not Result in Substantial Improvement in Outcomes

Such improvements may require a more fundamental change in clinical approach than that required by the PCMH model. Moreover, as clinical care has been estimated to influence only $20 \%$ of health outcomes, ${ }^{16}$ PCMH-based improvement in medical care alone may not be sufficient.

\section{Cost Impact Difficult to Demonstrate}

The model may affect health care costs only within populations where there exists high opportunity for cost control. Patients with high costs are a minority in most practices, making cost impact difficult to demonstrate.

\section{Demonstrating Value}

The 2 initiatives showing the most substantial impact on quality and on cost or utilization-the Vermont Blueprint for Health and the Comprehensive Primary Care Initiative $(\mathrm{CPCI})$ — provide substantial resource support for PCMH transformation and care delivery. The Vermont Blueprint for Health makes available practice transformation assistance and community programs for care management, self-management support, and care coordination. Its 2013 Annual Report compared $100 \mathrm{PCMH}$-recognized practices with 60 control practices having similar patient demographics and illness profiles, and found lower total cost, inpatient admissions, and specialty care visits for Medicaid patients in the PCMH-recognized group. ${ }^{17}$ Similarly, although only first-year results are currently available, practices in the Centers for Medicare \& Medicaid Services CPCI, which received supplemental care management fees from the Centers and other payers averaging $\$ 70,045$ per clinician, achieved reductions for some regions in total cost, hospitalizations, emergency department use, and readmissions, and improvement in quality metrics for some regional high-risk populations, relative to comparison practices. ${ }^{18}$
Although patient experience metrics have been included in some studies assessing the impact of the $\mathrm{PCMH}$, they have generally been based on Consumer Assessment of Healthcare Providers and Systems (CAHPS) ratings. ${ }^{19}$ As such, they focus on appointment access, front desk staff performance, and physician communication, missing the most important dimensions of patient-centered value: how patients feel and function, whether their health goals have been achieved, the nature of their relationship with clinicians, and their capacity for self-care.

In view of the shortcomings of existing studies and their results, we set out to develop a framework for defining patient-centered value and a model to guide primary care practices in delivering such value.

\section{PATIENT-CENTERED PRIMARY CARE VALUE FRAMEWORK}

Value is defined as "the material or monetary worth of

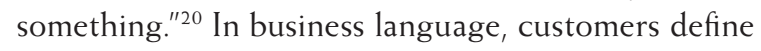
value by quantifying what they would pay for a service or product. In the language of health care, patients or persons define value by expressing what they want from care and what they or their payers will pay for it.

Notwithstanding a decade of espousing patientcentered care, research defining patient value is limited and is generally based on authors' personal opinions or where empirical, on operational service elements. ${ }^{21-23}$

In our experience, which is derived from several decades of work supporting health care quality improvement, 5 concepts can be used to describe what patients value: health, cure, healing, preconditions of health, and experience of care.

1. Health is understood as a high level of experience and functioning across physical/somatic, cognitive/emotional, social/productive, and spiritual dimensions, and the capacity for maintaining them.

2. Cure is the restoration of a high level of experience and functioning in 1 or more of the dimensions of health, most often the physical/somatic.

3. Healing is improvement in the cognitive/ emotional and spiritual dimensions, integrated with improvement in physical/somatic and social/productive dimensions. Healing is experienced through transcendence of the suffering that comes with illness, integration of its meaning with our life story, and achievement of functional potential. ${ }^{24-26}$

4. Preconditions of health include support for housing, food, jobs and income, and activities of daily living.

5. Finally, experience of care is based on perceived access, relationship, technical excellence, and amenities.

People differ in the emphasis that they place on these 5 components of value. Generally, healthy people 


\section{Figure 1. Patient-centric care value framework.}

\begin{tabular}{|c|}
\hline Health \\
Cure \\
Healing \\
Preconditions Support \\
Experience of Care
\end{tabular}$\div$ Cost $=$ Value

value optimization and maintenance of health. Cure is highly valued where it is possible, particularly in acute situations. Healing is valued in chronic illness, alongside support for the preconditions of health in disadvantaged or disabled populations. Most of us value the experience of care.

We propose a patient-centered value framework based on these concepts, in which value is quantified by what patients are willing to pay for the components (directly or through insurance), as shown in Figure 1. It is consistent with, but more patient centered than, the most widely accepted current vision-the so-called triple aim of improving quality and population health while reducing cost. ${ }^{27}$

\section{THE PRIMARY CARE VALUE MODEL}

In developing a model that incorporates value, we used Michael Porter's concept of the value chain, defined as a set of activities that an organization engages in to create value for its customers. ${ }^{28}$ Although his original analysis was applied to the manufacturing industry, he has since applied it to health care ${ }^{29,30}$ and more specifically to primary care. ${ }^{31}$ In our view, his formulation, although useful in guiding analysis of process efficiency, does not adequately describe what patients value nor provide a sufficient road map for primary care transformation.

Instead, we propose that value creation in primary care can be achieved by applying a primary care value model (PCVM) having 3 tiers of additive and complementary activities as depicted in Figure 2. The tiers are (1) foundational activities providing organizational infrastructure, (2) direct care activities providing medical and complementary services, and (3) care coordination activities providing coordination and support for direct care activities. We discuss each in detail below.

\section{Foundational Activities}

Many health care organizations, including primary care practices, are organized around the provision of services for which there is reimbursement (public, commercial insurance, or individual self-payment) under conditions that are defined by organizational leadership and clinicians, without explicitly taking the needs and wants of patients into account. The PCMH model seeks to provide a vision for improving primary care, but is not sufficiently focused on understanding patient value and providing a road map for its creation.

Transformation in the PCVM is based on a set of foundational activities that lay the groundwork for understanding and creating value for patients (Figure 2), including:

- Defining organizational vision and customer values

- Developing a clinical and business model

- Creating organizational infrastructure

- Implementing information technology infrastructure Many organizational improvement and transformation programs begin with defining organizational vision. Through this process, the organization achieves

\section{Figure 2. The primary care value model (PCVM).}

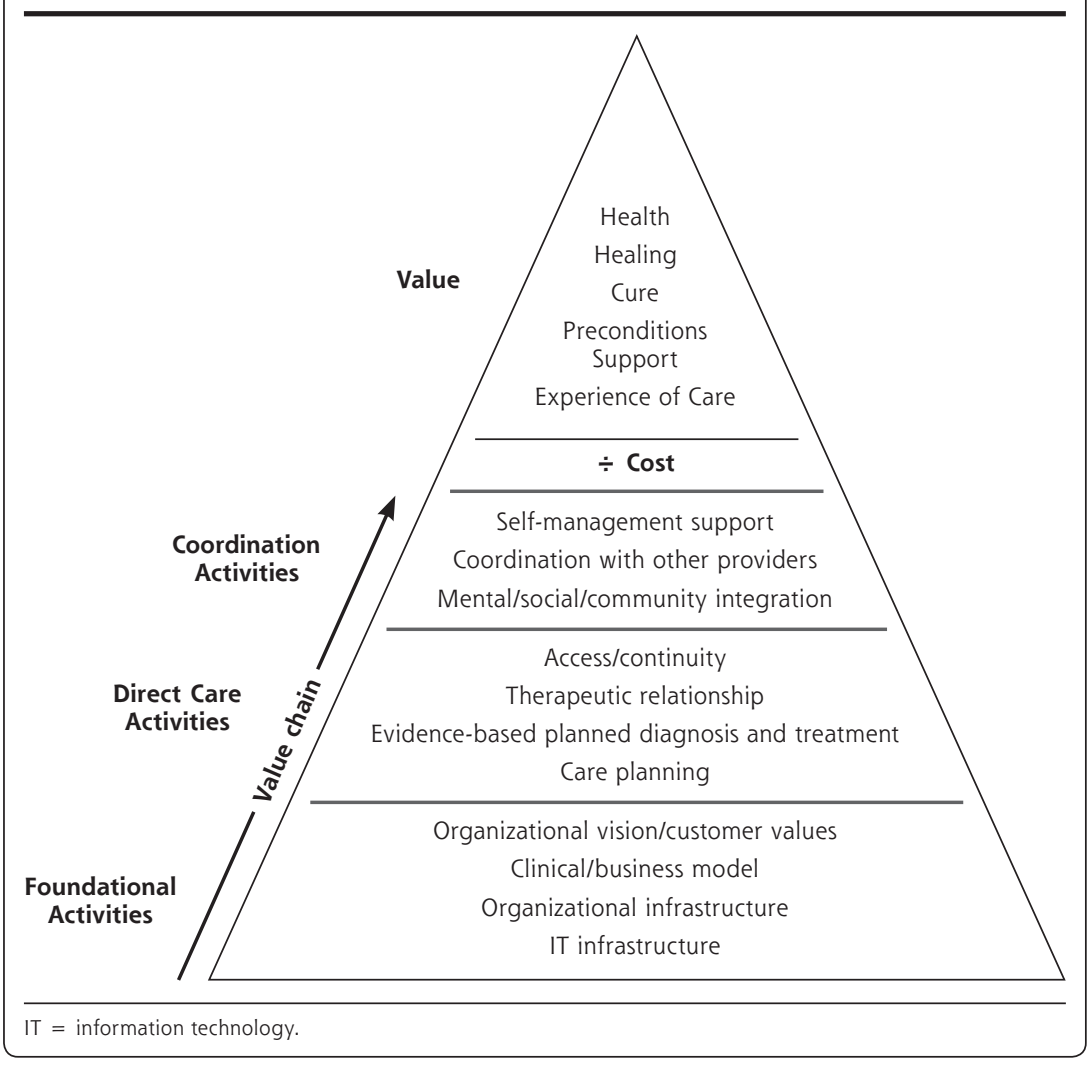


clarity regarding what it wants to accomplish for organizational leadership, clinicians and staff, payers and financial sponsors, and patients and the community.

Alongside of clarifying vision, it is essential to determine what patients value. The patient-centered value framework described in the preceding section conceptualizes components of value and how they may differ across patient subgroups. Primary care practices should explicitly assess what their patients want.

On the basis of such assessment, the organization must next determine the clinical model that it will deploy. Examples of value-centered clinical models are as follows:

- Acute care model—brief appointments, same-day access, use of mid-level practitioners

- Chronic care model—planned visits, team-based care, care planning, and self-management support

- Low-socioeconomic status and disability modelchronic care model with patient navigational support, and with integration of social, behavioral, and community resources

- Healing-focused and integrative medicine modelextended visits, therapeutic relationship, and complementary care services

Clinical models must be financially viable, so in addition to specifying its clinical model, the organization must develop a business model that explicates and justifies costs (administrative, clinician) and revenues (payer and self-pay).

Organizational infrastructure includes reporting structure and accountability, culture, and performance measurement and improvement. Performance measures that reflect organizational mission and patient values, that assess performance of clinical and business models, and for which individuals or operating units are accountable are a key component of such infrastructure.

Information technology is essential to efficient and reliable primary care practice, in both the administrative domain (practice management, billing, financial, scheduling, efficiency analytics) and clinical domain (ordering, results, documentation, care planning and coordination, population segmentation, asynchronous access, efficiency/effectiveness analytics). In appropriate patient populations, information technology should be able to reduce practice costs through the use of portals that shift scheduling and financial/billing responsibilities to patients, much as other industries (eg, air travel) have reduced cost by requiring customers to do scheduling and payment work, ${ }^{32,33}$ as well as through applied analytics.

\section{Direct Care Activities}

The value that patients seek from primary carehealth, healing, cure, support, and experience-results largely from direct patient care. We propose that 4 activities are critical to value creation: (1) ensuring access and care continuity, (2) developing a therapeutic relationship, (3) providing evidence-based, planned diagnosis and treatment, and (4) engaging patients through care planning (Figure 2).

Traditionally, access and continuity have been thought of as enabling patients to get timely appointments and receive after-hours advice by telephone; the former has been the focus of advanced-access scheduling, with mixed results. ${ }^{34}$ Some practices have developed extended hours for urgent care as a mechanism to address avoidable emergency department visits; others have ceded this activity to urgent care clinicians. Enhanced access and continuity are critical enablers of a therapeutic relationship. Practices that focus on these aspects are increasingly making communications available to patients via telephone and a web portal or e-mail, ${ }^{35}$ and are working out mechanisms for channeling communications to appropriate staff in care teams. ${ }^{36,37}$

The therapeutic relationship is increasingly understood to be central to health and healing and to the patient experience. Most research on this topic has been in psychiatric and psychological care, where effective relationships with therapists have been shown to be associated with better care outcomes. ${ }^{38}$ In primary care, work has begun to address 2 aspects of effective therapeutic relationships: how clinicians can foster them ${ }^{39}$ and how planners can organize workflow to allow time for their development. ${ }^{40}$ Additionally, how to cover their cost in the context of existing insurance payment programs is an issue that has driven the development of concierge or selfpayment practice arrangements that typically offer extended visits.

Diagnostics and therapeutics are generally understood to be the cornerstone of medical care, and most practices focus their efforts on achieving excellence in this area. Studies of ambulatory care quality, however, document both diagnostic error and unreliability. ${ }^{41,42}$ System-based continuous quality measurement and improvement around evidence-based care pathways seeks to address these deficiencies.

For many patients with chronic illness, however, such improvements in care fall short of engendering healing. The integrative medicine clinical care model has developed as a response. As described by the Institute for Functional Medicine, this model guides clinicians in an approach to understanding and responding to illness based on a matrix of underlying biopsychosocial systems, and seeks to support healing through integration of relationship-based conventional and complementary services. ${ }^{43}$ 
Care planning is not generally viewed as an essential value-creating activity, but it should be. In care planning, patients' health goals are elicited; actions to achieve them are identified, assigned to team members, and carried out; and the plan is revised based on results. In chronic illness, outcomes depend on patient engagement around self-defined goals and involvement in self-care, and care planning brings support for these activities into conjunction with diagnostics and therapeutics. Studies are beginning to show impact when care planning is embedded in primary care practice and focused on populations with need. ${ }^{44-47}$

\section{Care Coordination Activities}

Although direct patient care activities most directly create patient-centered value, 3 types of coordinating activities are required for full impact: (1) coordinating care with other clinicians and patients, (2) supporting patients in self-management, and (3) integrating with sources of support for mental health and social services needs, and with community health initiatives (Figure 2).

Care coordination with other clinicians is a wellrecognized component of primary care. In today's complex health care environment, a critical aspect of the therapeutic relationship with a primary care clinician is the ability to see the patient as a whole person and to guide and coordinate care with specialists, hospitals, rehabilitation facilities, and others. Care coordination with patients is sometimes referred to as population or panel management ${ }_{i}$ it involves outreach to patients for appointments and other services, and in some populations, support for navigation through the complex health care system.

Given their preponderant impact on health outcomes ${ }_{1}^{16}$ provision of support for self-management of diet, exercise, and stress is essential for facilitating health and healing.

Many patients require additional coordination and support as part of the healing process. Integration with mental health care is required for patients with substance addictions, depression, anxiety, attention deficit disorder, and other psychological or psychiatric conditions. For patients having low socioeconomic status, support for food, housing, and education or employment needs is often integral to healing. Patients with disability may have similar or more specific support needs. Given that many of the underlying factors that influence individual and population health for such patients are in the community, achievement of healing and health requires coordination with community health initiatives by documenting needs and connecting patients with such community development efforts. ${ }^{48}$

\section{IMPLICATIONS}

Our analysis has 3 implications. First, metrics used to evaluate $\mathrm{PCMH}$ impact, recognition, and payment should better reflect what patients value. Specifically, we recommend including metrics for the following:

- Self-reported outcomes. The Patient-Reported Outcomes Measurement Information System (PROMIS) measure set is publicly available and can be implemented for longitudinal tracking of pain, fatigue, anxiety, depression, and physical and social functioning. ${ }^{49}$

- Healing. The Self-Integration Scale is a 16-item survey that seeks to provide longitudinal measurement of attributes that might be affected by healing. ${ }^{50}$

- Therapeutic relationship. The consultation and relational empathy (CARE) measure is based on a 10 -item questionnaire that seeks to assess aspects of the practitioner relationship..$^{51,52}$

- Self-management capacity. Measures of patient activation ${ }^{53}$ or patient enablement ${ }^{54,55}$ can form a basis for assessing the capacity to manage one's health.

Second, in our view, making transformation more value driven will require a model that is based on a framework of patient-centered values. We offer such a framework and model (Figures 1 and 2, respectively), and in the Supplemental Appendix (http://www.AnnFamMed.org/content/14/2/159/supp1/DC1/) provide 2 illustrative scenarios for the use of the model in practice transformation. We believe that our work builds on prior efforts by Wagner et $\mathrm{al}^{56}$ in the Chronic Care Model and by Bodenheimer et $\mathrm{a}^{157}$ in "The 10 Building Blocks of High-Performing Primary Care," by providing a model based on explicit patient value that can serve as a road map for transformation.

Third, we advocate for more substantial resources to support primary care practices in transformation and to fund research and development of effective implementation of activities in our PCVM. As noted, the 2 projects that are strongest in demonstrating impact of the $\mathrm{PCMH}$ model are those in which practices received substantial funding for transformation and ongoing delivery of care. Lack of resources compromises efforts of practices to incorporate care planning and care coordination, and to use the integrative medicine model to create effective therapeutic relationships and provide complementary and healthoriented services. Research and development is needed to better implement these activities, more effectively support self-management and achievement of health, and integrate primary care with mental and social services and community health initiatives.

To read or post commentaries in response to this article, see it online at http://www.annfammed.org/content/14/2/159. 
Key words: primary care; transformation; patient-centered medical home; $\mathrm{PCMH}$; value; value chain; healing

Submitted April 5, 2015; submitted, revised November 5, 2015; accepted November 11, 2015.

Funding support: Funding for this work was provided by the Primary Care Development Corporation.

- Supplementary materials: Available at http://www.AnnFamMed. org/content/14/2/159/suppl/DC1/.

\section{References}

1. American Academy of Family Physicians, American Academy of Pediatrics, American College of Physicians, American Osteopathic Association. Joint principles of the patient-centered medical home. http:// www.aafp.org/dam/AAFP/documents/practice_management/pcmh/ initiatives/PCMHJoint.pdf. Published Feb 2007. Accessed Jan 19, 2015.

2. Peikes D, Zutshi A, Genevro JL, Parchman ML, Meyers DS. Early evaluations of the medical home: building on a promising start. Am J Manag Care. 2012;18(2):105-116.

3. Jackson GL, Powers BJ, Chatterjee R, et al. Improving patient care. The patient centered medical home. A systematic review. Ann Intern Med. 2013;158(3):169-178.

4. Patient-Centered Primary Care Collaborative. The medical home's impact on cost and quality: an annual update of the evidence, 2013-2014. http://www.pcpcc.org/resource/medical-homes-impactcost-quality. Published Jan 2015. Accessed Jan 19, 2015.

5. Fifield J, Forrest DD, Burleson JA, Martin-Peele M, Gillespie W. Quality and efficiency in small practices transitioning to patient centered medical homes: a randomized trial. J Gen Intern Med. 2013;28(6):778-786.

6. The Patient-Centered Medical Home Initiative in New York State. Report to the State Legislature April 2013. https://www.health. ny.gov/health_care/medicaid/redesign/docs/pcmh_initiative.pdf. Published Apr 2013. Accessed Jan 19, 2015.

7. Friedberg MW, Schneider EC, Rosenthal MB, Volpp KG, Werner RM. Association between participation in a multipayer medical home intervention and changes in quality, utilization, and costs of care. JAMA. 2014;311(8):815-825.

8. International RTI. Evaluation of the Multi-Payer Advanced Primary Care (MAPCP) Demonstration: First Annual Report. January 2015. http://innovation.cms.gov/Files/reports/MAPCP-EvalRpt1.pdf. Published Jan 2015. Accessed Jan 19, 2015.

9. Friedberg MW, Rosenthal MB, Werner RM, Volpp KG, Schneider EC. Effects of a medical home and shared savings intervention on quality and utilization of care. JAMA Intern Med. 2015;175(8):1362-1368.

10. Schwenk TL. The patient-centered medical home: one size does not fit all. JAMA. 2014;311(8):802-803.

11. Abrams M. Medical homes: an evolving model of primary care. http://www.commonwealthfund.org/Blog/2014/Feb/Medical-HomesEvolving-Primary-Care.aspx. Published Feb 25, 2014. Accessed Jan $19,2015$.

12. Jackson GL, Williams JW Jr. Does PCMH "work"? - the need to use implementation science to make sense of conflicting results. JAMA Intern Med. 2015;175(8):1369-1370.

13. National Committee for Quality Assurance. 2014 PCMH Standards and Guidelines. https://inetshop01.pub.ncqa.org/publications. Accessed Jan 19, 2015.

14. The Joint Commission. Primary Care Medical Home Self-Assessment Tool. http://www.jointcommission.org/accreditation/pchi.aspx. Published May 15, 2014. Accessed Jan 19, 2015.
15. Utilization Review Accreditation Commission (URAC). PatientCentered Medical Home, Version 2. https://www.urac.org/ wp-content/uploads/STDGlance_PCMH_v2-01.pdf. Published 2013. Accessed Jan 19, 2015.

16. University of Wisconsin Population Health Institute. County health rankings - our approach. http://www.countyhealthrankings.org/ourapproach. Accessed Jan 19, 2015.

17. Department of Vermont Health Access. Vermont Blueprint for Health 2013 Annual Report. http://hcr.vermont.gov/sites/hcr/files/pdfs/VTBlu eprintforHealthAnnualReport2013.pdf. Accessed Jan 19, 2015.

18. Mathematica Policy Research. Evaluation of the Comprehensive Primary Care Initiative: First Annual Report. http://innovation.cms.gov/ Files/reports/CPCI-EvalRpt1.pdf. Published Jan 2015. Accessed Feb 7, 2015.

19. Agency for Healthcare Research and Quality. CAHPS Clinician \& Group. https://cahps.ahrq.gov/surveys-guidance/cg/index.html. Accessed Jan 19, 2015.

20. Oxford English Dictionary. http://www.oxforddictionaries.com/us/ definition/american_english/value. Accessed Jan 19, 2015.

21. Detsky AS. What patients really want from health care. JAMA. 2011; 306(22):2500-2501.

22. McKinley RK, Middleton JF. What do patients want from doctors? Content analysis of written patient agendas for the consultation. $\mathrm{Br}$ J Gen Pract. 1999;49(447):796-800.

23. Papp R, Borbas I, Dobos E, et al. Perceptions of quality in primary health care: perspectives of patients and professionals based on focus group discussions. BMC Fam Pract. 2014;15(1):128.

24. Egnew TR. The meaning of healing: transcending suffering. Ann Fam Med. 2005;3(3):255-262.

25. Hsu C, Phillips WR, Sherman KJ, Hawkes R, Cherkin DC. Healing in primary care: a vision shared by patients, physicians, nurses, and clinical staff. Ann Fam Med. 2008;6(4):307-314.

26. Cassell EJ. The Nature of Healing: The Modern Practice of Medicine. New York, NY: Oxford University Press; 2013.

27. Berwick D, Nolan T, Whittington J. The triple aim: Care, cost, and quality. Health Aff (Millwood). 2008;27(3):759-769.

28. Porter ME. Competitive Advantage: Creating and Sustaining Superior Performance. New York, NY: Simon and Schuster; 1985.

29. Porter ME. What is value in health care? N Engl J Med. 2010;363 (26):2477-2481.

30. Kaplan RS, Porter ME. The big idea: how to solve the cost crisis in health care. Harv Bus Rev. https://hbr.org/2011/09/how-to-solve-thecost-crisis-in-health-care. Published Sep 2011.

31. Porter ME, Pabo EA, Lee TH. Redesigning primary care: a strategic vision to improve value by organizing around patients' needs. Health Aff (Millwood). 2013;32(3):516-525.

32. Lawrence D. Footing the bill: patient portals, part 1. Healthcare Informatics. 2009. http://www.healthcare-informatics.com. proxy-hs. researchport.umd.edu/article/footing-bill-patient-portals-part-i. Cited Aug 23, 2015. Accessed Jan 19, 2015.

33. Gamble KH. Is it registering: patient portals, part 2. Healthcare Informatics. http://www.healthcare-informatics.com. proxy-hs. researchport.umd.edu/article/it-registering-patient-portals-part-ii. Published 2009. Accessed Aug 23, 2015.

34. Rose KD, Ross JS, Horwitz LI. Advanced access scheduling outcomes: a systematic review. Arch Intern Med. 2011;171(13): 1150-1159.

35. North F, Crane SJ, Chaudhry R, et al. Impact of patient portal secure messages and electronic visits on adult primary care office visits. Telemed J E Health. 2014;20(3):192-198.

36. Bodenheimer T. Lessons from the trenches-a high-functioning primary care clinic. N Engl J Med. 2011;365(1):5-8. 
37. Goldberg DG, Beeson T, Kuzel AJ, Love LE, Carver MC. Team-based care: a critical element of primary care practice transformation. Popul Health Manag. 2013;16(3):150-156.

38. Del Re AC, Flückiger C, Horvath AO, Symonds D, Wampold BE. Therapist effects in the therapeutic alliance-outcome relationship: a restricted-maximum likelihood meta-analysis. Clin Psychol Rev. 2012;32(7):642-649.

39. Scott JG, Cohen D, Dicicco-Bloom B, Miller WL, Stange KC, Crabtree BF. Understanding healing relationships in primary care. Ann Fam Med. 2008;6(4):315-322.

40. Rakel DR. The salutogenesis-oriented session: creating space and time for healing in primary care. Explore (NY). 2008;4(1):42-47.

41. Singh $H$, Meyer AN, Thomas EJ. The frequency of diagnostic errors in outpatient care; estimations from three large observational studies involving US adult populations. BMJ Qual Saf. 2014;23(9):727-731.

42. Schuster MA, McGlynn EA, Brook RH. How good is the quality of health care in the United States? Milbank Q. 1998;76(4):517-563, 509.

43. Jones DS, Hoffmann L, Quinn S. 21st Century Medicine: A New Model for Medical Education and Practice. Gig Harbor, WA: The Institute for Functional Medicine; 2010. https://www.functionalmedicine.org/ files/library/21st-century-medicine_001.pdf. Accessed Jan 19, 2015.

44. Peikes D, Chen A, Brown R. Effects of care coordination on hospitalization, quality of care, hospitalization, and health care expenditures among Medicare beneficiaries: 15 randomized trials. JAMA. 2009;301(6):603-618.

45. Boult C, Leff B, Boyd CM, et al. A matched-pair cluster-randomized trial of guided care for high-risk older patients. J Gen Intern Med. 2013;28(5):612-621.

46. Boult $C$, Reider $L$, Leff $B$, et al. The effect of guided care teams on the use of health services: results from a cluster-randomized controlled trial. Arch Intern Med. 2011;171(5):460-466.

47. Steele GD, Haynes JA, Davis DE, et al. How Geisinger's advanced medical home model argues the case for rapid-cycle innovation. Health Aff (Millwood). 2010;29(11):2047-2053.
48. Folsom Group. Communities of solution: the Folsom Report revisited. Ann Fam Med. 2012;10(3):250-260.

49. National Institutes of Health. PROMIS measures. http://www. nihpromis.org/measures/measureshome. Accessed Jan 19, 2015.

50. Meza JP, Fahoome GF. The development of an instrument for measuring healing. Ann Fam Med. 2008;6(4):355-360.

51. Mercer SW, Maxwell M, Heaney D, Watt GC. The consultation and relational empathy (CARE) measure: development and preliminary validation and reliability of an empathy-based consultation process measure. Fam Pract. 2004;21(6):699-705.

52. Mercer SW, Howie JGR. CQI-2-a new measure of holistic interpersonal care in primary care consultations. Br J Gen Pract. 2006; 56(525):262-268.

53. Hibbard JH, Mahoney ER, Stock R, Tusler M. Do increases in patient activation result in improved self-management behaviors? Health Serv Res. 2007:42(4):1443-1463.

54. Howie JGR, Heaney DJ, Maxwell M, Walker JJ. A comparison of a Patient Enablement Instrument (PEI) against two established satisfaction scales as an outcome measure of primary care consultations. Fam Pract. 1998;15(2):165-171.

55. Banerjee A, Sanyal D. Dynamics of doctor-patient relationship: a cross-sectional study on concordance, trust, and patient enablement. J Family Community Med. 2012;19(1):12-19.

56. Wagner EH, Austin BT, Von Korff M. Organizing care for patients with chronic illness. Milbank Q. 1996;74(4):511-544.

57. Bodenheimer T, Ghorob A, Willard-Grace R, Grumbach K. The 10 building blocks of high-performing primary care. [Reproduced with permission of the UCSF Center for Excellence in Primary Care.] Ann Fam Med. 2014;12(2):166-171. 